\title{
SEISMIC PERFORMANCE OF TRADITIONAL URBAN ARCHITECTURE IN MOROCCO
}

\author{
K. EL HARROUNI ${ }^{1}$, H. KHARMICH ${ }^{1}$ \& A. LAMZAH ${ }^{2}$ \\ ${ }^{1}$ Ecole Nationale d'Architecture, Rabat, Morocco. \\ ${ }^{2}$ Institut National d'Aménagement et d'Urbanisme, Rabat, Morocco.
}

\begin{abstract}
The urban and architectural heritage of Moroccan medinas has received national and international awareness and increased interest since the early 1980s. To reinforce the protection and preservation of this heritage, judicial and political means were set up in the early 20th century and have been revised several times since then. Despite efforts on both national and international levels, the physical degradation of the historic cities and the unhealthy living conditions of the people in those cities still constitute a threat to the protection and preservation of this valuable cultural and architectural heritage. The medinas are currently subject to continuous degradation caused by overpopulation, uncontrolled tourism and the forced intrusion of modern functions and non-adapted structures into the historical fabric. In the past decades, a gentrification movement has been observed in Moroccan medinas. This movement has mainly been characterized by the return of richer and middle class population (Moroccan residents and foreign tourists) who reinvested traditional houses of modest size. They help in the restoration of degraded buildings and change the spaces around them. The traditional techniques of consolidation are based mainly on relatively simple and corrective interventions. These techniques use traditional methods, materials and tools. They are easy to implement and can be carried out by small-sized companies, within the particular context of medinas (high-density housing, hazard, presence of inhabitants, etc.). In addition, most of the urban and architectural heritage has been exposed to violent earthquakes, which caused partial destruction and seriously damaged the heritage structures. Usually after such events, new construction techniques were adopted. These types of techniques are still in use today and have proven their efficiency throughout the centuries. A sampling of these local construction practices apparent in the medinas is presented in this paper. The paper also proposes a protection strategy of the historic buildings. It combines conservation requirements with safety, within the restoration of historic city centres, which should help in selecting adequate and efficient techniques that respect local culture and limit future damage.

Keywords: historic buildings and monuments, local seismic culture, medina, protection strategy, rehabilitation, restoration, urban and architectural heritage.
\end{abstract}

\section{INTRODUCTION}

\subsection{Background}

Traditional urban architecture in Morocco is mainly found in the medinas or pre-colonial towns. These medinas are not only the physical environment composed of inhabitants and places of activities; they are also a social space characterized by historical, cultural and spiritual values. The way of life and the social traditions are the reflections of civilization, which appears even in design, constructions and space organizations. The medina, the oldest section and the historic heart of some Moroccan cities (31 medinas as shown in Fig. 1), is an example of this type of urban space organization until the colonial period. Moreover, its urban space was the result of a slow and integrative evolution of an urban and architectural production adapted to the needs of the community and to a framework of life, with habitat, equipment and activities its principal components. An analysis of the pre-colonial urban design of Moroccan medinas demonstrates how the built environment is more than a mere representation or reflection of social order or a mere environment in which socialization takes place. Rather, physical and spatial forms 


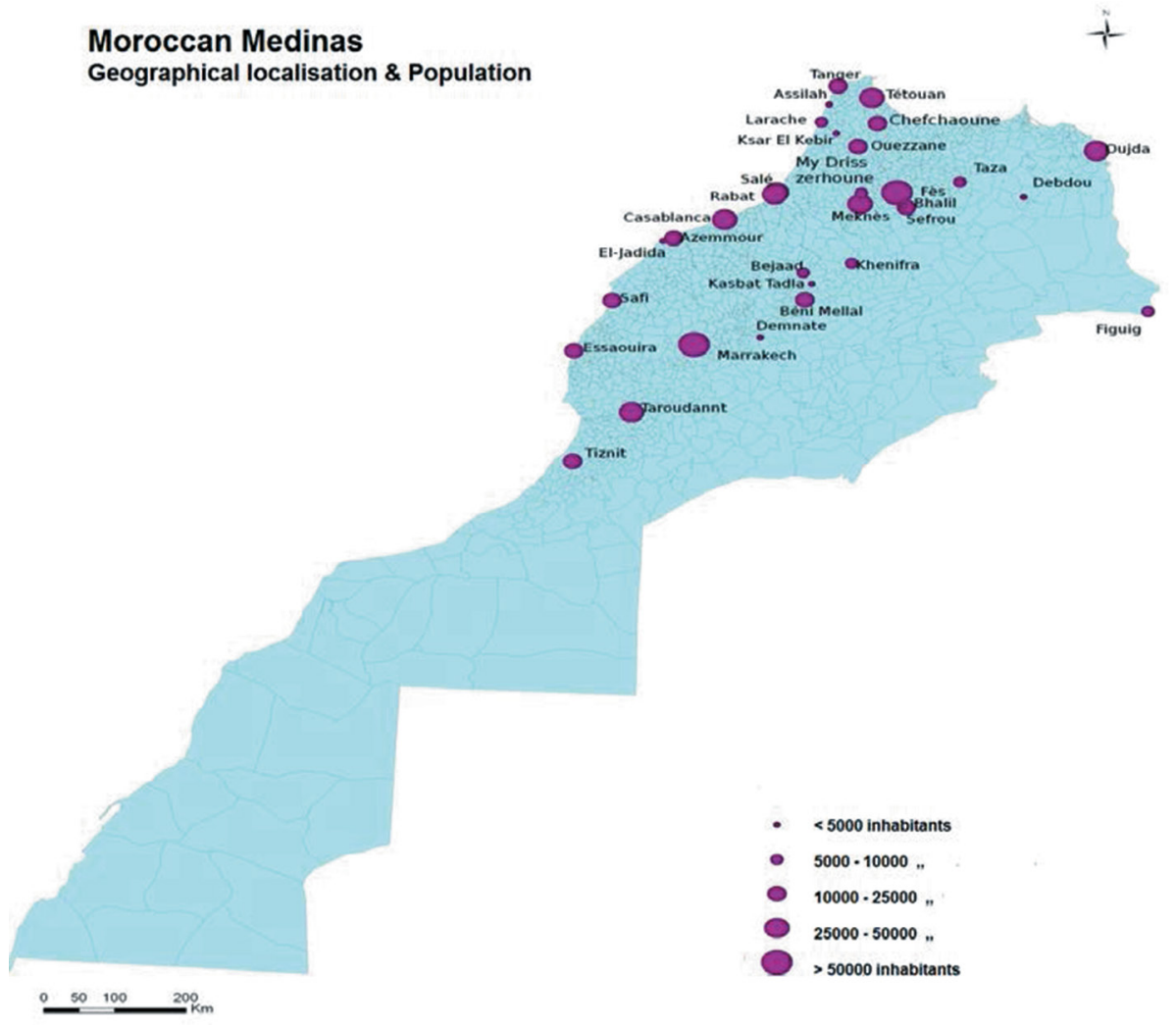

Figure 1: Moroccan medinas: geographical localization and population (HCP [1]).

actually constitute as well as represent much of social and cultural existence. Society is to a very large extent constituted by the very buildings and spaces it creates.

The urban macro-form of the medina is distinguished by two elements: the city centre and the quarters. Both are surrounded by city walls including gateways. This primary classification leads to several typologies of equipment based on a hierarchy, according to their importance and localization in the city:

- The first-level structuring equipment is in the centre: the large mosque, the market, the caravansaries (stables, shops and accommodations) and medersa or religious school.

- The second-level equipment is located in the quarter or 'Haouma': public bath or 'Hammam' and koranic school.

- The third-level equipment is located in the quarter street (a public street in a residential quarter): some shops for daily supply for families.

\subsection{Classification of monumental buildings}

The main historic and monumental buildings in the medina include mosques, minarets, palaces, riads, traditional houses, medersas, foundouks, walls, gates, triumphal arches and fountains (Figs. 2-6). 

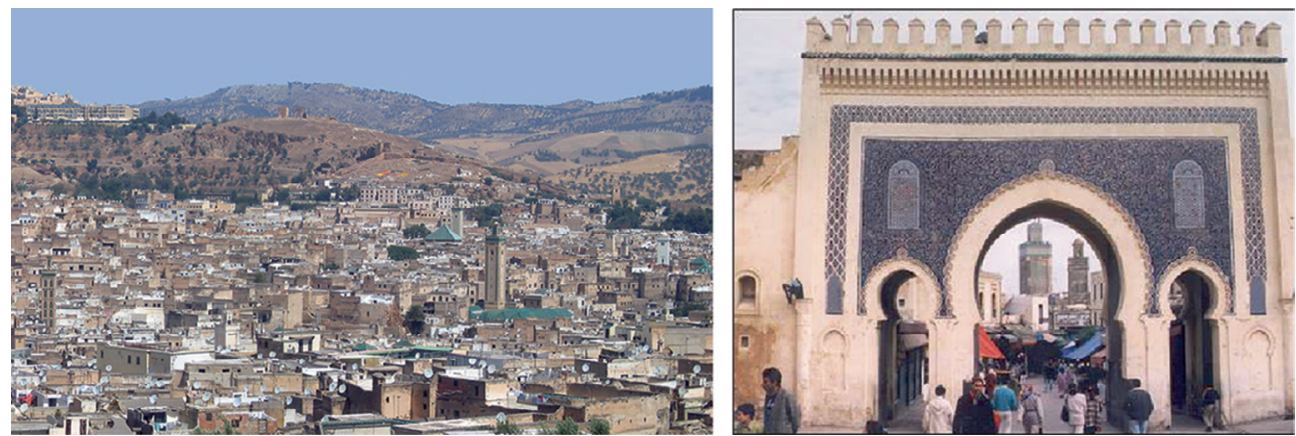

Figure 2: Ancient urban tissu, Fez medina and Fez Gate.
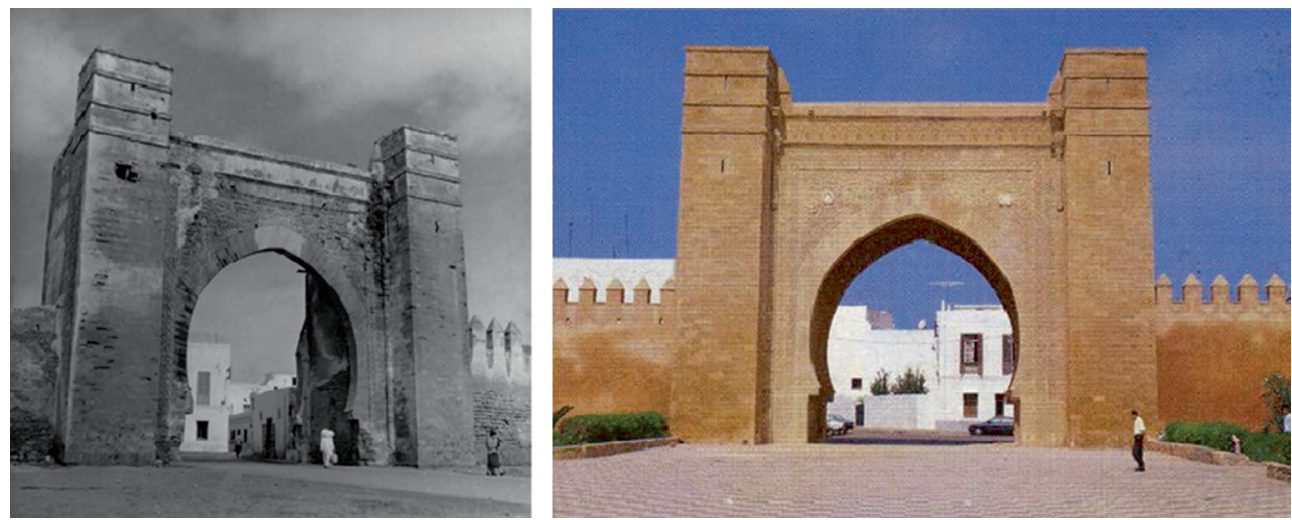

Figure 3: Mrissa Gate, Sale medina (1910 and today).
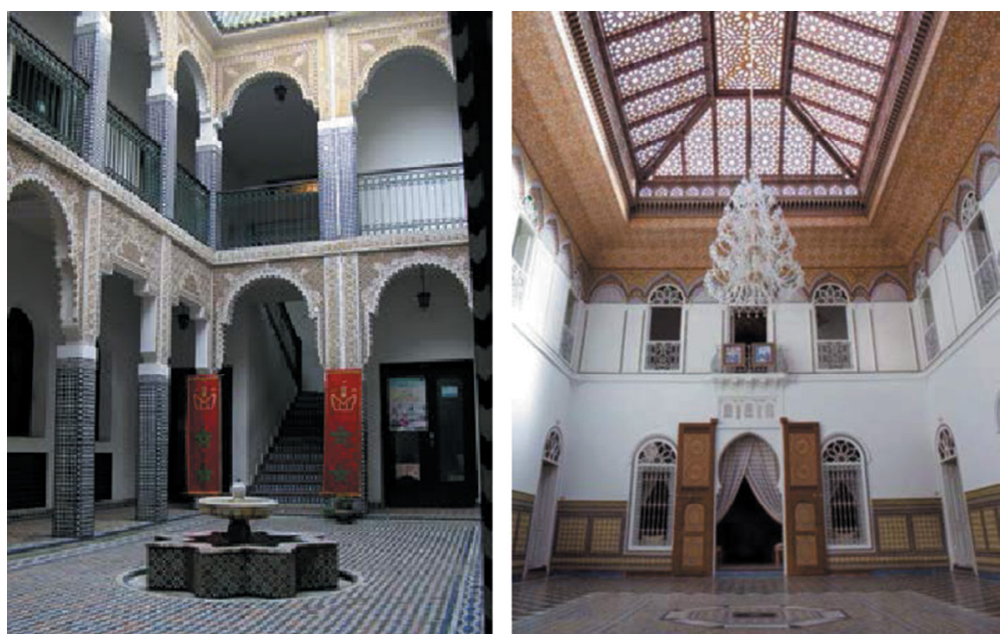

Figure 4: Rehabilitated foundouk in Meknes medina and Palace in Asilah medina. 

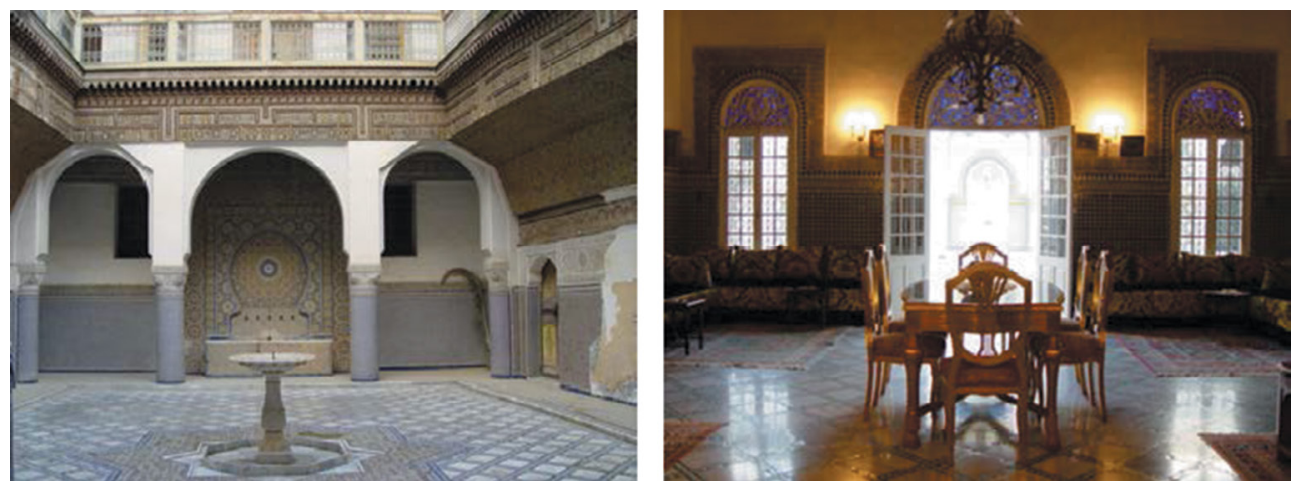

Figure 5: Reconversion of historic houses and palaces in Fez medina.
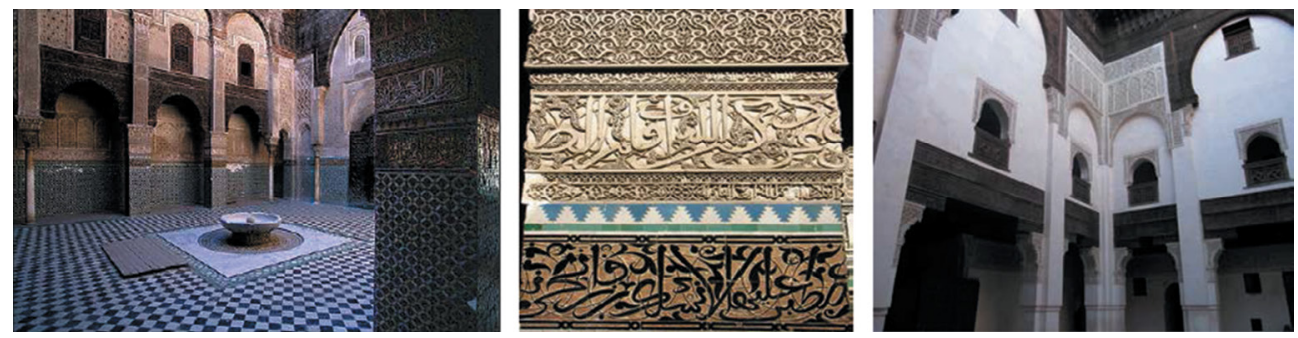

Figure 6: The Attarin and Cherratin medersas, Fez medina.

\subsection{World heritage sites in Morocco}

The Moroccan urban and architectural heritage has received national and international awareness and increased interest since the early 1980s. Owing to the attention and concerns over the preservation of historic monuments and the urban fabric, some historic cities have become part of UNESCO's list of the world's cultural heritage sites. UNESCO added to this list the medina of Fez in 1981, Marrakech in 1985, Meknes in 1996, Tetouan in 1997, Essaouira in 2001, the Portuguese fortified city of Mazagan in 2004 and recently the city of Rabat in 2012. Rabat is considered a 'modern capital and historic city: a shared heritage'. Currently, the city of Casablanca is a candidate for inclusion in the above list.

To reinforce the protection and the preservation of these historic centres, judicial and political means were set up in the early 20th century and have been revised several times since then. Despite efforts on both national and international levels, the physical degradation of the historic cities and the unhealthy living conditions of the people in those cities still constitute a threat against the protection and preservation of this valuable cultural heritage. The medinas are currently subject to continuous degradation caused by overpopulation, promotion of tourism and the forced intrusion of modern functions and structures into the historical fabric. The overpopulation in the housing areas has led to spatial subdivision of the interiors, and additional stories are built according to methods which are totally in discordance with local building traditions. Furthermore, the necessary maintenance of traditional buildings has not always been realized. The cause behind this is either a lack of the know-how techniques of traditional building construction or a financial problem due to limited financial resources of the occupants. The built environment then underwent continuous physical and structural degradation. 


\section{HISTORICAL BUILT ENVIRONMENT}

2.1 Damage and pathologies of historical and traditional constructions

Under the effects of aging and the lack of maintenance, a large number of traditional buildings in the medinas face structural problems. This situation is further exacerbated by successive transformations and modifications, some of which are clearly visible. In many cases, due to overdensification, extensions were added without taking into account the structural capacity of the buildings and the load which the walls could bear. Thus, in some cases, floors were added to historical houses using new building materials such as reinforced concrete, hollow concrete blocks, modern bricks and cement-sand mortar.

The major problems of traditional constructions (Fig. 7) are mainly due to the following factors:

- Overloading, overutilization and overdensification of the buildings

- Ground subsidence

- Aging of materials

- Deterioration and filling of the traditional evacuation pipes and overflow of used water

- Capillary increase of moisture in the walls

- Water sealing problems

- The collapse of a number of houses leading to many empty spaces which weaken the neighbouring buildings and make them more vulnerable to earthquakes and other hazards.

\subsection{Retrofitting and reinforcement techniques}

In the past decades, a gentrification movement has been observed in Moroccan medinas. This movement has mainly been characterized by the return of richer and middle class population (Moroccan residents and foreign tourists) who reinvested in traditional houses of modest size. They help in the rehabilitation of degraded buildings and thus change the spaces around them. Morocco is an interesting and significant example of this process because the medinas are sometimes well preserved. Indeed, this process is currently a lever to revitalize historical
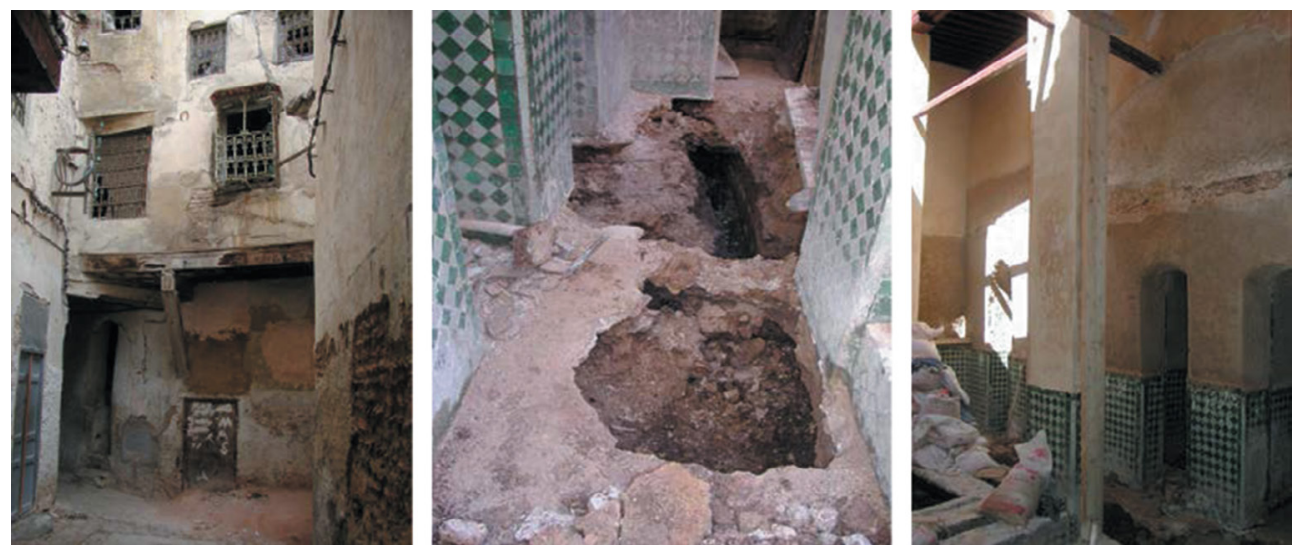

Figure 7: Degraded historic built environment: degradation of facades, walls and foundations (Hassouni [2]). 
fabrics and to revive their residential and commercial functions within vaster urban spaces. It is important to mention here that this process should be controlled in order to avoid serious transformations in the traditional spatial layout and urban design of Moroccan medinas.

The traditional techniques of consolidation are based on relatively simple and corrective interventions. These techniques use traditional methods, materials and tools. They are easy to implement and can be carried out by small-sized companies, within the particular context of medinas (high-density housing, hazard, presence of inhabitants, etc.).

Due to the large number of damaged buildings in some medinas (Fez, for example, Fig. $8-11$ ), propping is adopted as a provisional solution to avoid the risk of collapse and to allow the sustenance of the walls and the floor and thus the recovery below the foundations, the repair of masonry, the replacement and the repair of the floors, etc. The following main steps are usually used in retrofitting of damaged buildings:

- Visual inspection and follow-up of the phenomenon

- Propping

- Foundation consolidation

- Repair of the walls and stitching

- Consolidation of the floors

- Repair of the ceilings
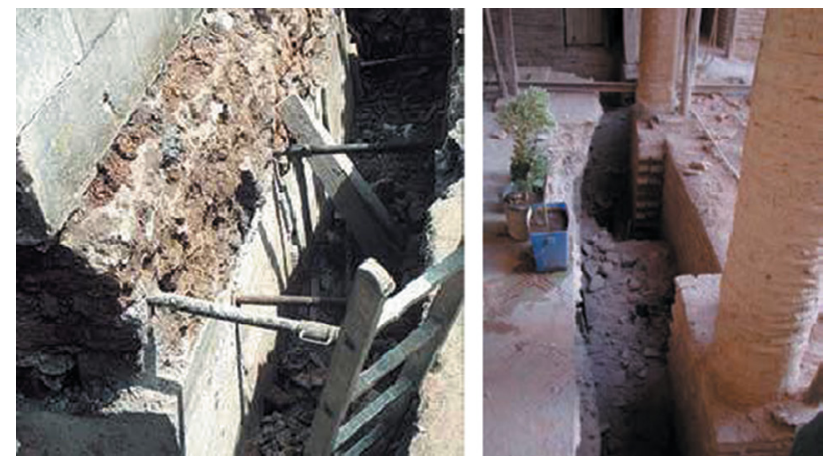

Figure 8: Underpinning work by rebuilding the foundation step by step or by using micropiles to strengthen the foundation with pressure cement grouting (Hassouni [2]).
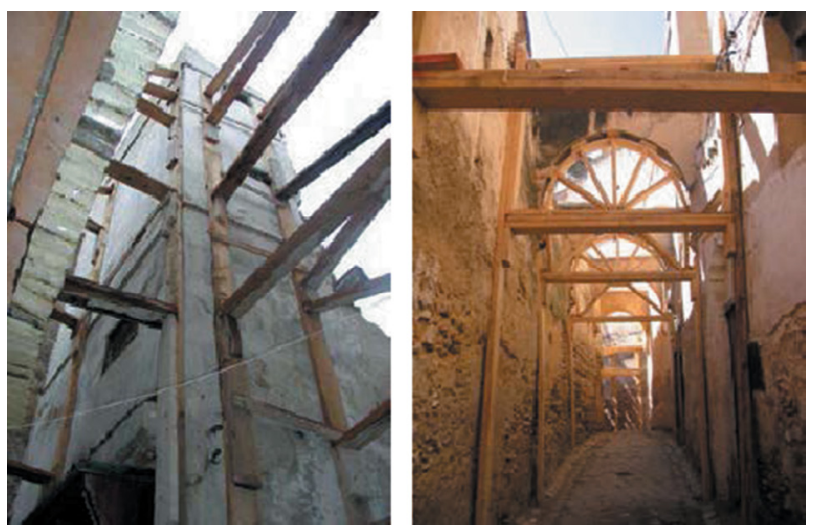

Figure 9: Example of propping of damaged buildings in Fez. 

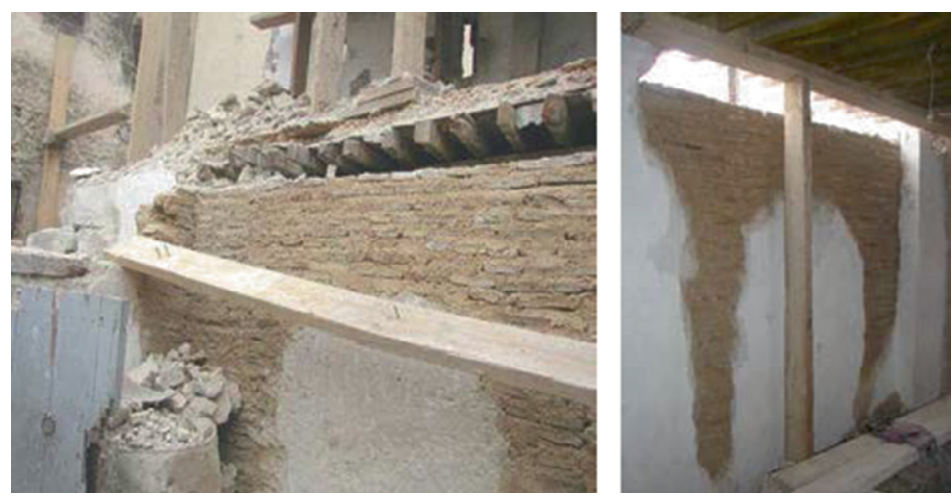

Figure 10: Repair of masonries, 'restitching' of fissures and re-establishing of the junction between the walls and the floors (Hassouni [2]).
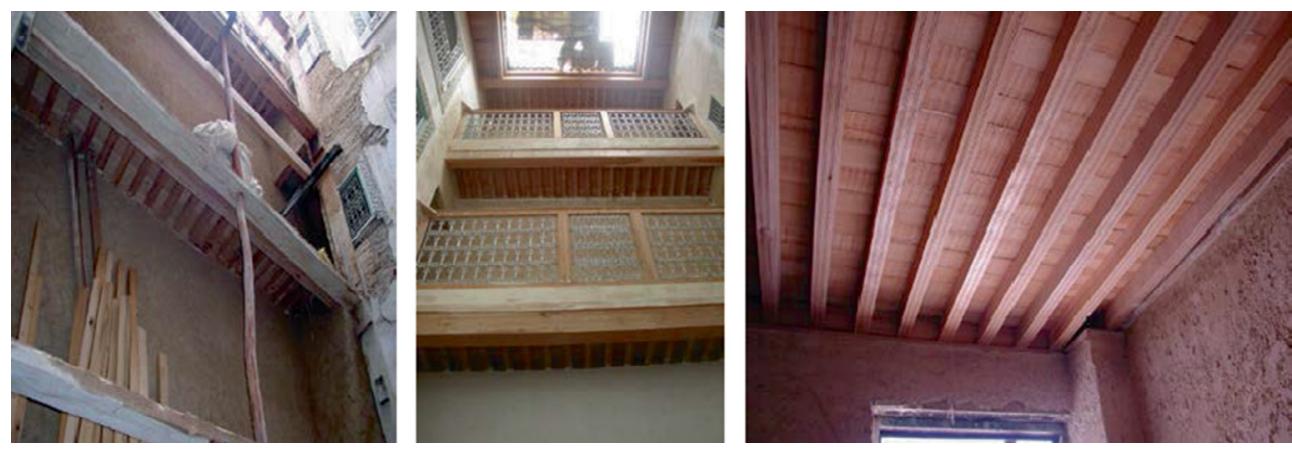

Figure 11: Reconstitution of the destroyed parts of the courtyard (Hassouni [2]).

\subsection{Local aseismic building techniques: local seismic culture}

Most of the historical buildings and monuments are located in the semi-active seismic zones, which accelerate their vulnerability. These constructions should be preserved over time, especially against earthquakes which have a low annual probability of occurrence but high probability of causing significant damage to the structures.

According to documented sources of historical seismicity and research carried out in this field (El Mrabet [3]), the heritage structures have been affected on several occasions by violent earthquakes. Of course, the ancient communities knew of the seismicity of the region and the significant aspects required of the built environment. They reacted by applying constructive techniques in their habitats and also in the public and religious buildings. This constituted a local 'seismic culture' which resulted from a specific know-how and specific prevention measures.

Developed countries are nowadays rapidly developing technologies to restore and to rehabilitate historic buildings and are paying more attention to the cultural value of historic buildings. In this context a critical re-evaluation of traditional techniques is being developed, 
especially those concerning the restoration of monuments. Moreover, the loss of certain technical expertise is rarely compensated by up-to-date know-how. Even buildings constructed with aseismic techniques are carelessly modified and techniques which are still applicable are abandoned.

A technical regulation for earthquake-resistant buildings with only earth was established but the regulations (RPS 2011 [4]) of the building code requirements for earthquakes in Morocco ignore traditional aseismic technologies and thus minimize their value. Structures of architectural heritage and traditional urban housing, by their very nature and history, present a number of challenges in diagnosis and restoration, which limit the application of the code. To protect the historically built environment in order to reduce losses, a critical reevaluation of traditional aseismic technologies can indeed result in more effective prevention, a more appropriate relief action and less harmful rehabilitation. In many seismic regions, the traditional rules applied to old constructions can often be employed in recent masonry constructions carried out by using stone and earth. It is necessary to reconsider traditional attitudes towards older constructions in the medinas and historic villages situated in the seismic regions. Effective protection measures can be implemented by re-evaluating the so-called local seismic cultures (Helly [5]; Karababa [6]) in combination with the knowledge of local aseismic building techniques.

\section{THE SEISMIC PERFORMANCE OF HISTORIC BUILDINGS}

\subsection{Morocco's historical seismicity}

The geological position of Morocco at the centre of several interacting tectonic plates is the reason why, historically, Moroccan cities were repeatedly destroyed by several strong earthquakes. Some cities were partially or totally destroyed. Indeed, the seismic events in Morocco were seldom reported in the historical documents and archives, as well as in those which deal with Islamic world history and those related to the specific history of Morocco. Chronological and spatial details are missing in the information which has been recorded on the earthquakes in Morocco. In contrast, the foreign sources which address the history of Morocco have been much more interested in the earthquakes. As a matter of fact, several earthquakes have been mentioned in the foreign sources but are not found in the Moroccan historical archives. Certain earthquakes were quite detailed but in general there was confusion of events and an exaggeration of the material and human losses. Research work by El Mrabet [7] has significantly contributed to the study of this historical seismicity by using the maximum of available sources - Arab, Spanish, Portuguese and French. The richness of these data depended on the intensity of the seism and the proximity of the epicentre to historical, cultural and political cities, such as Fez, Marrakech and Meknes in the centre of Morocco, or to economic locations like the Atlantic harbours of Tangier in the north and Agadir in the south. From the 9th to the 11th century, the earthquakes were described in a brief way: the writings referred to the destruction of constructions without other precise details. The description became relatively more detailed but the objective remained purely informative. It was in the 17th century that the details of the 1624 and 1663 earthquakes were found reported in a particular mail: the damages which affected the buildings in Fez were mentioned in a detailed manner. The extent of the destruction of the 1755 seism, the Lisbon earthquake, was mentioned by several sources: the destruction concerned even the palaces and the mosques in Meknes while the damage was less impressive in Fez. 
In addition, a chronology of the great earthquakes in Morocco since the year 881 has been presented (La Grande Encyclopédie du Maroc [8]):

- On 28 May 881, an appalling seism affected the two banks of the strait.

- On 1 and 30 December 1079, a devastating seism destroyed towers, minarets and buildings. Many people perished under the ruins.

- In 1276, a violent earthquake caused the destruction of Larache located on the Atlantic coast, causing several deaths.

- On 22 September 1522, Fez and the villages of the surrounding areas were completely destroyed; the seism also caused severe damage in Tetouan in the north of Morocco.

- On 26 January 1531, a violent seism was felt in Morocco but this event is unknown in Moroccan literature.

- The earthquake recorded on 1 March 1579 in Mellilia destroyed scores of houses and part of the ramparts of the city.

- On 11 May 1624, a catastrophic seism destroyed most of the Moroccan towns of Taza, Fez and Meknes. This earthquake is relatively well documented in Moroccan literature.

- On 5 August 1660, the town of Mellilia was affected by a violent seism causing considerable damage.

- In July 1719, the Moroccan coastal towns recorded a violent seism, which also destroyed part of the town of Marrakech.

- On 27 December 1722, a devastating seism caused large damages in the Moroccan coastal towns.

- In 1731, another seism destroyed the town of Santa Cruz (Agadir).

- On 1 November 1755, the seism which struck Lisbon destroyed the majority of the Moroccan coastal towns from Tangier to Agadir. At that time, the most important cities, like Fez, Marrakech and Meknes, were located in the interior of the country. One of the welldocumented destructive tsunamis was in the Atlantic Ocean. The Arabic and European archives provide us with important information concerning the event. About 26 days after the Lisbon earthquake, a stronger and more violent seism affected the city of Fez after the last prayer of the day: many minarets and mosques were destroyed in different places in the city and about 10,000 persons were killed.

- On 15 April 1757, a violent seism destroyed several buildings of Sale town.

- On 12 April 1773, a devastating seism almost destroyed the town of Tangier and several houses in Fez collapsed. This earthquake was also felt in Sale.

- On 31 August 1792, Mellilia was again shaken by a violent earthquake causing the destruction of several buildings.

- On 11 February 1848, a disastrous earthquake was felt in Morocco causing considerable damage in Mellilia.

- On 21 and 22 January 1909, a seism destroyed rural agglomerations located $5 \mathrm{~km}$ from Tetouan, resulting in hundreds of casualties.

- On 4 January 1929, an earthquake damaged Fez and the surrounding villages.

- On 29 February 1960, a devastating earthquake of magnitude 5.7 on the Richter scale destroyed Agadir causing about 12,000 deaths; the damages estimated at that time were US 290 million dollars.

- On 28 February 1969, a violent seism, which had its epicentre in the same area as that of the 1755 (Lisbon) seism, was felt in almost all of Morocco, but it was on the Atlantic Littoral that this seism reached its strongest intensity. 
- On 26 May 1994, an earthquake of magnitude 5.7 on the Richter scale shook the town of Al Hoceima.

- On 24 February 2004, the Al Hoceima province recorded a violent seism of 6.3 on the Richter scale causing the collapse of 2,539 houses including 2,498 in rural areas.

What is interesting in this chronology is the frequency of the earthquakes which struck the town of Fez (1046, 1079, 1408, 1522, 1623, 1624, 1708, 1755, 1773, 1776, 1867), so much that its inhabitants believed that the ground of their city often moved because it was hollow and full of subterranean water.

\subsection{The seismic design code for buildings}

Morocco is located at the extreme northwest tip of Africa, in a region which constitutes a plate boundary between the African and Eurasian plates. Figure 12 shows the seismicity recorded in Morocco and its neighbouring regions in the period 1990-2007. To the north of Morocco, a line of strong seismicity extends from the Strait of Gibraltar, all the way to the Atlantic Ocean. This line of seismicity reflects the interactions between the colliding African and Eurasian plates at the boundary which separates them.

Figure 12 strongly indicates that, within continental Morocco, seismic activity is mostly concentrated along the Rif and the Atlas mountain belts, the Rif intermountain belt in northernmost Morocco being the most active. Although the seismicity is less frequent in the Atlas mountains, the height of these structures along with the ongoing seismic activity indicates that these mountain belts are capable of producing large destructive earthquakes such as that of Agadir in 1960.

The new version of the national code of building requirements for earthquakes (RPS 2011 [4]) provides the main seismic zones and the corresponding acceleration coefficients with a

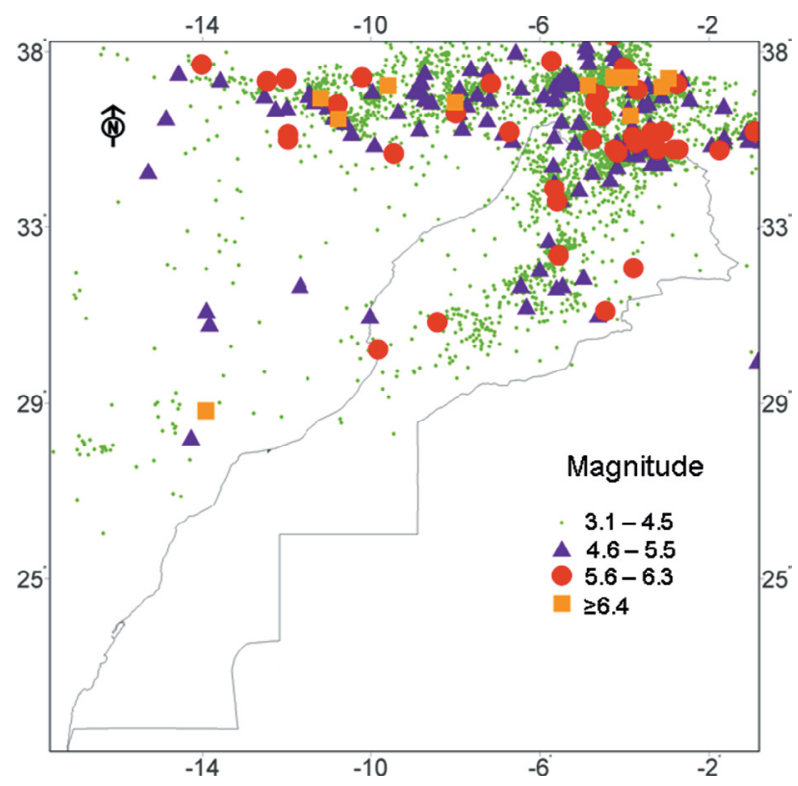

Figure 12: Morocco's seismicity map (1900-2007; CNRST [9]). 


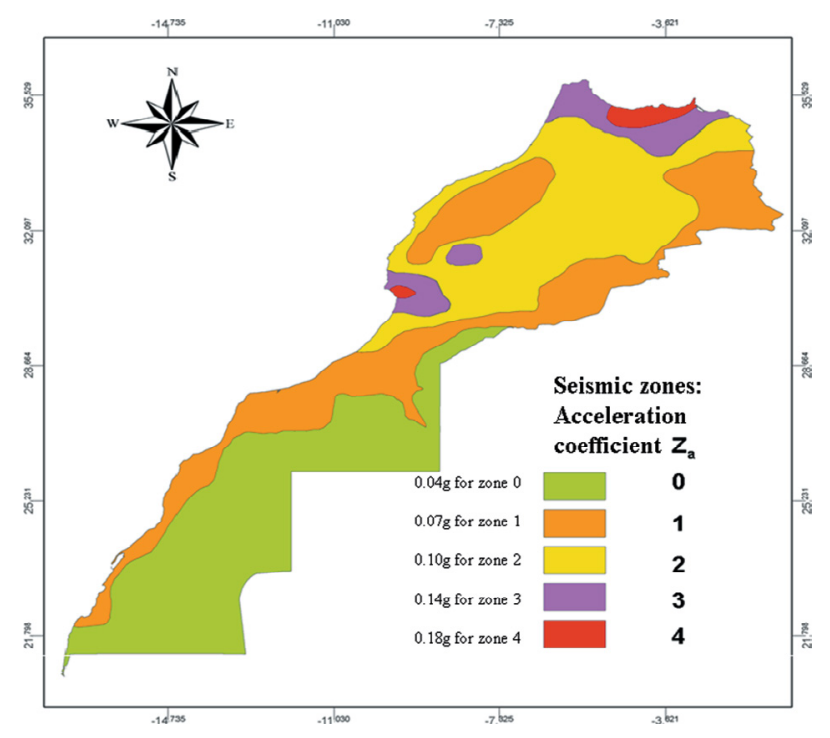

Figure 13: Seismic zones (five zones instead of three in the code's first version) (RPS 2011 [4]).

$10 \%$ exceedance probability in 50 years; this information is given in Fig. 13, including five, instead of three, zones in the first version elaborated in 2000, with accelerations which vary between $4 \mathrm{~g}$ and $18 \mathrm{~g}$.

\subsection{The built heritage face to earthquakes}

A medina like Fez is regarded as a good example of the experiment of the old frame face to the earthquakes. In addition to the morphologically compact architecture of the old frame, the knowledge of the local construction practices is fundamental and should guide the choice for successive restoration and rehabilitation operations. The principal building materials used in the construction include hearth blocks, plaster, lime mortar, wood and stone. Traditional ceramic tiles, 'zelij', and cedar woodwork are the common finishing materials. Indeed, one of the constructive typologies of the load-bearing wall structure is the masonry carried out with earth bricks and bound by loam mortar or lime, between which are intercalated wood elements of cedar. This provision of two materials, one rigid and the other flexible, allows absorption of the seismic horizontal loads. The renovation and restoration work on the other hand has been done with mostly traditional materials and methods of construction. Local masons and craftsmen do the majority of the work.

\section{LOCAL CONSTRUCTION PRACTICES}

\subsection{Introduction to seismic rehabilitation}

Throughout history, some of the old medinas located in seismic areas have been exposed to violent earthquakes which caused partial destruction and seriously damaged their buildings. Usually after such an event, new specific construction techniques were adopted. Some anomalies as shown in Fig. 14 are apparent in the old frame and they correspond to a change 


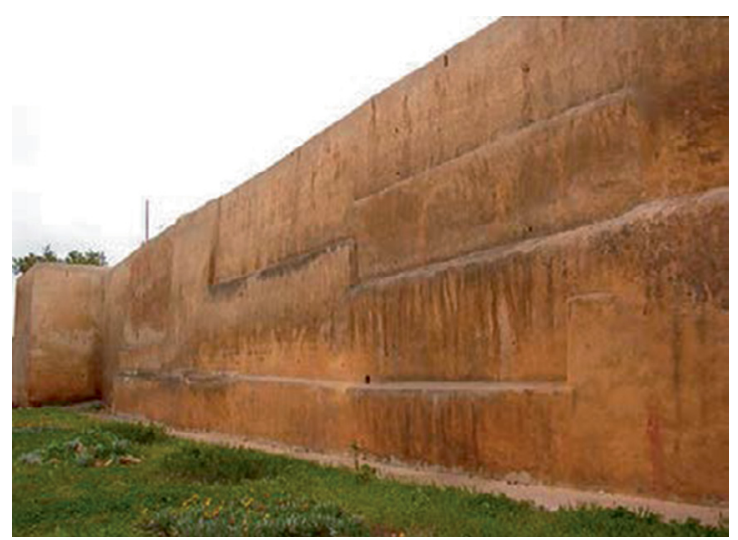

Figure 14: Example of anomalies - Sale medina rampart.

in constructive methods, aimed at restoring, rehabilitating, or solving the structure stability problem. The frame thus modified will be naturally exploited and the solution which has been found will be reused if it proves to be good. The anomaly introduced into the frame will then change step by step to a voluntary anomaly and be classified as a local constructive practice and as an answer to any event, an earthquake for example (Ferrigni [10]).

A sampling of the local construction practices apparent in the medinas has been presented (El Harrouni [11,12]). These techniques consist of using longitudinal ties made of wood within masonry walls, arches to transfer horizontal seismic loads to the floors, contrasting arches and 'sabat', discharging arches and framed openings, round-shaped wood pieces to allow rotary movements at the feet of the arches, buttresses, reinforced basement and the rebuilt angle chaining. These traditional methods could then be developed as being soft 'paraseismic' measurements (Laurenti [13]) applicable to the old frame for the protection and conservation of the historical architectural heritage. They are still in use today in medinas and have proven their efficiency throughout the centuries.

\subsection{Buttresses}

When a frontage wall or a great wall presents a cant, the response of the community to this problem is almost always the same: the use of a buttress (Fig. 15), a mass of masonry built against a wall to strengthen it. This system is a consolidating element to the existing structure and it is generally added to an older masonry building. Sometimes, the buttress is carried out during construction, a voluntary and premeditated act to reinforce this construction, generally at the corners of the structure. In earthquake-prone areas, the buttress frequently accompanies the stone frame and becomes an essential element to achieve building stability. Sometimes, the buttresses were used as both utilitarian and decorative forms. They can also be used as staircases, ensuring access to the dwelling, built to play the role of confortement, a judicious way to associate reinforcement technique with comfort.

The unreinforced masonry structures have very low stress levels and their stability, not strength, governs the safety; but the geometry changes may threaten the stability of the structure. For high-vaulted buildings, the arch will collapse and the buttress will remain standing in most cases. A masonry buttress will fracture at collapse, reducing its load capacity. 

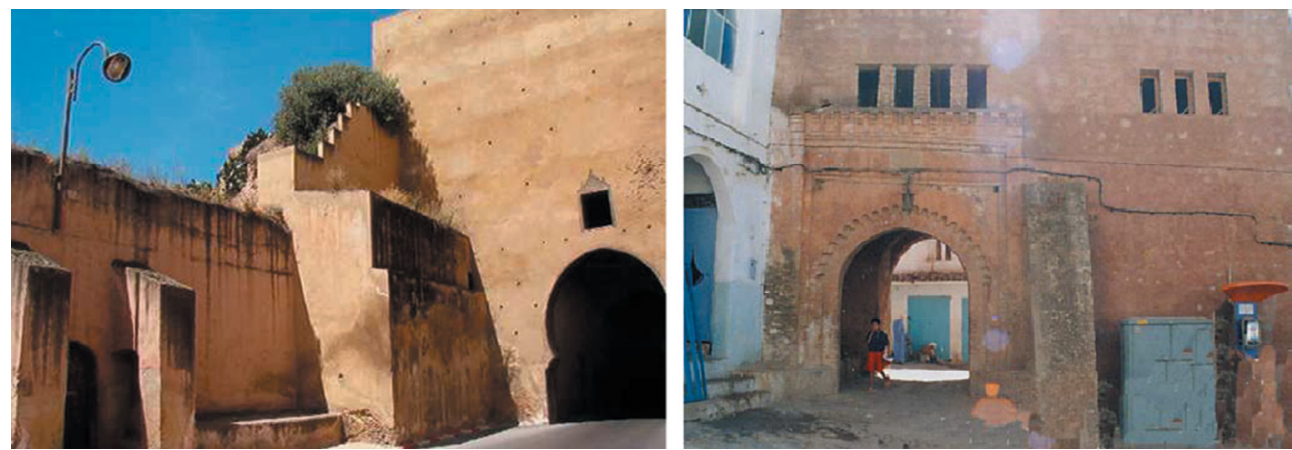

Figure 15: Use of buttress in Meknes medina rampart and Chefchaouen medina.
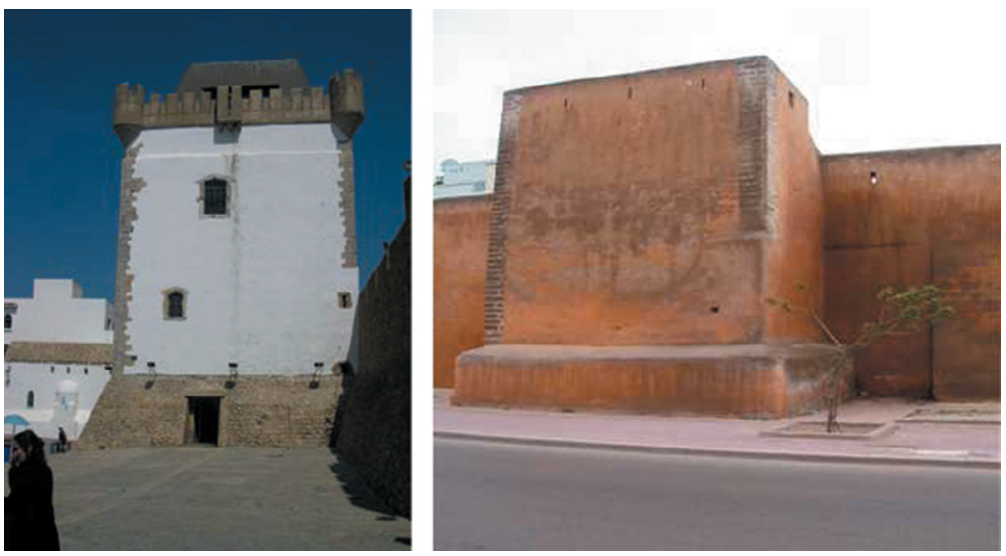

Figure 16: Al Kamra Tower in Asilah medina and Rampart in Sale medina.

\subsection{The basement and the vertical reinforcing chains}

The basement should be high to ensure a stable base on which a building is raised, a historic monument for example (Fig. 16). The vertical reinforcing chain made of cut stone is another means of reinforcement and consolidation of the building corners, which is generally used in colonial architecture and fortified architecture. These techniques, when used with a material other than the original masonry of the traditional building, decrease the seismic performance of the building. It also causes an aesthetic damage to the building because the new material stays visible and visually reduces the appearance of the building.

\subsection{Contrasting arches and roofed passageways or sabats}

The urban structure of the medina is badly affected by the constraints of the site and is organized in an irregular network of narrow streets which are rarely rectilinear; these streets surround the blocks and separate them from each other, allowing them a dynamic behaviour during the earthquakes. These separating spaces play the role of an empty joint of separation. This urban morphology and building construction with narrow streets are probably a solution to reduce seismic damage and prevent the houses from collapsing. 

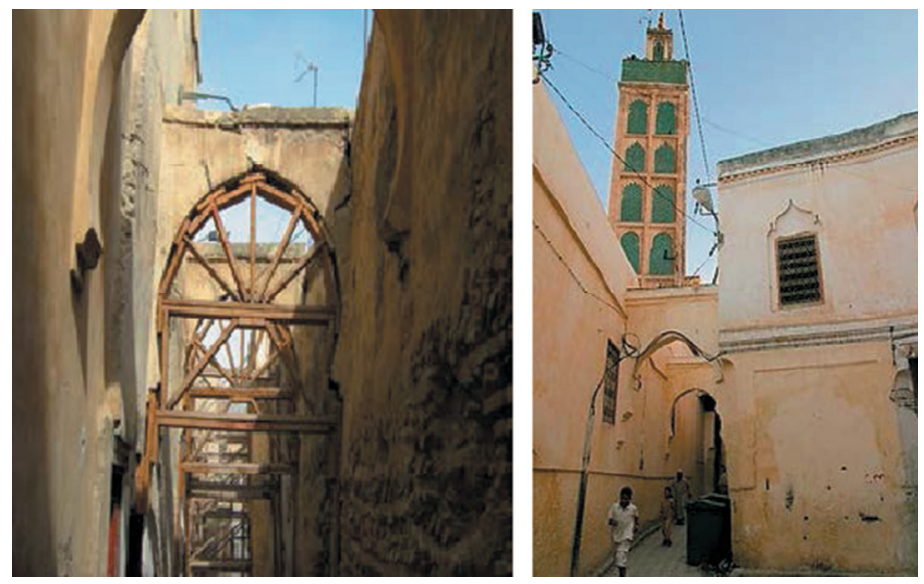

(a)
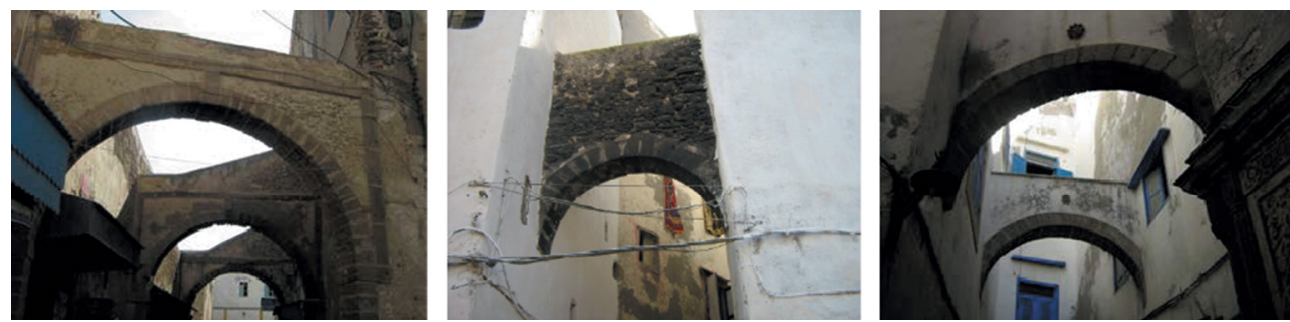

(b)
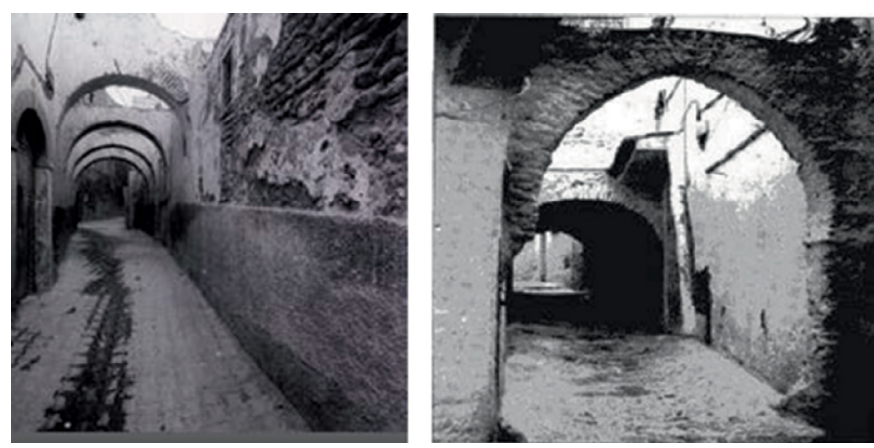

(c)
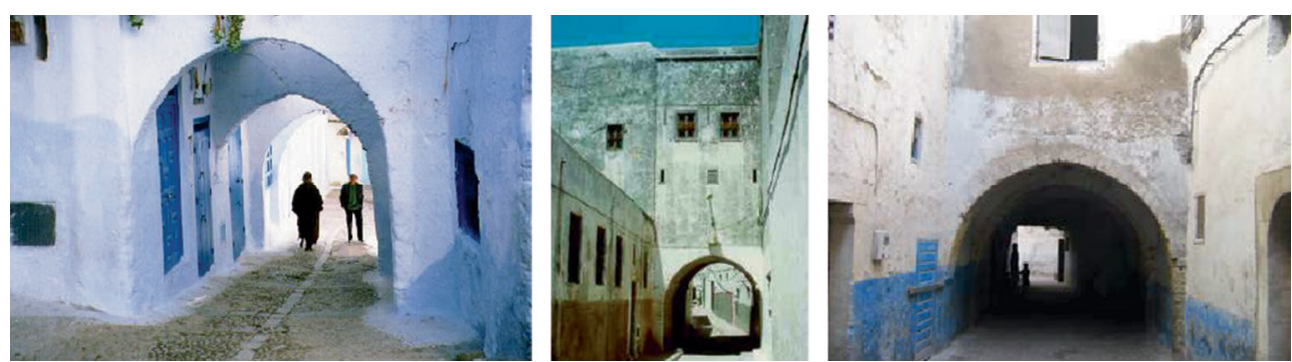

(d)

Figure 17: Contrasting arches in (a) Fez and Meknes medinas, (b) Essaouira medina and (c) Chefchaouen medina and Azzemour medina. (d) Sabats in Chefchaouen, Rabat and Essaouira medinas. 
The houses are semi-detached, overlapping and leaning against each other, thus forming a compact unit. Some streets are covered by galleries on top of which the houses extend, thus creating roofed passageways called the sabats. This extension is done on the top of the public space of the street, covering it forming a passageway, and constituting a physical link between the houses. (Abdessemed-Foufa [14]). These elements are realized either in vaults built out of stones or bricks with wooden incorporated logs. They constitute reinforcing elements by bracing the blocks and houses between each other. The houses form then a compact monolithic entity with a higher seismic resistance. Those are elements of reinforcement which determine the bracing of the blocks between themselves.

In addition, the urban framework of the medina is characterized by a certain number of arches built of stone or bricks, called confortement arches or contrasting arches whose relative flexibility and elasticity allow the transmission of the horizontal stresses to the ground. The buildings are not considered any more as isolated elements but as a compact dynamic block. This bracing is always present in the narrow streets of the medina and prevents the construction from collapsing (Fig. 17).

\subsection{Discharging arches and framed openings}

A discharging arch or relieving arch is an arch over a door, window or other opening, designed to distribute the pressure of the wall above. An opening in a frontage constitutes a vulnerable point in the event of deformation of the frame. The cracks on the front walls are found in the contours of the openings where the stresses are most significant and in particular close to the re-entrant angles. The earthquake-resistant design codes recommend, for masonry structures, rigid reinforced concrete and steel or wood framings for the openings, which, in principle, must be connected to the links of the walls. The wooden framings must be effectively connected to the masonry. The openings in the medina, doors and windows are framed by wood and well connected to masonry. Cut stone arcs are also located at the top of these openings (Fig. 18).

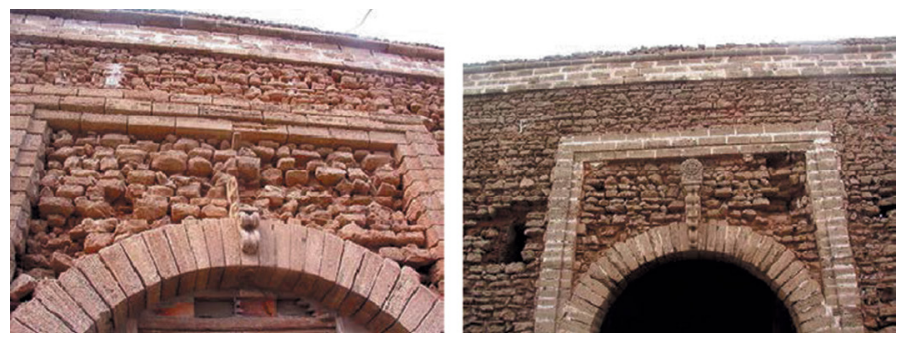

(a)
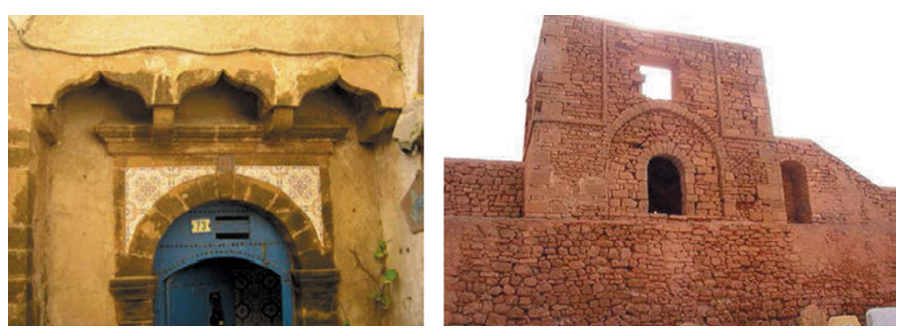

(b)

Figure 18: (a) Discharging arch and framed openings in Rabat extra-muros. (b) Framed openings in Essaouira medina and Sale medina. 

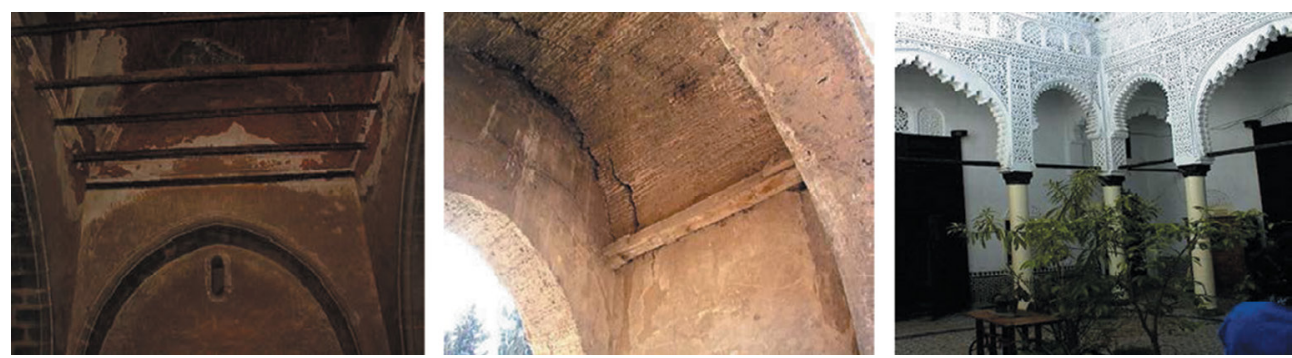

Figure 19: Use of bracing and wooden tie in Rabat, Meknes and Sale medinas.

\subsection{Arcades and wooden tie beam systems}

As mentioned earlier, bracing is one of the most significant aspects of earthquake-resistant design. The monolithic design in traditional architecture is a basic principle. According to this principle the various parts of a structure stay connected (Fig. 19), which prevents the dissociation of their elements under earthquake loads. This structural technique is realized mainly by the bracing arc, which binds two different masonry entities and links them to each other. They are consolidated by a wooden beam system which connects the frontages of the galleries to those of the load-bearing walls to ensure the stability of the walls with those of the interior and avoid their opening and collapse. Their distribution is rather regular and is particularly observed in the traditional courtyard houses.

The use of this linking system again shows the manner of the earthquake load resistance.

\section{HISTORIC BUILDINGS: PROTECTION STRATEGY}

The approach of combining conservation requirements with safety within the restoration of historic city centres is still not an obvious requirement for policymakers. Therefore, it is necessary to develop codes of practice which contain all available information on local seismic activity, original construction techniques and precarious situations, suggesting methods of validation of the proposed structural modifications. This should help those responsible for planning the actual site works to select adequate and efficient techniques, which respect the local culture and limit future damage (Lourenço [15]).

In order to preserve and protect historic buildings and monuments from the potential impacts of earthquakes, we first need to understand how ancient communities built their cities. Some protective arrangements listed above have been put in practice following site investigations in Moroccan medinas, including some historic monuments and traditional courtyard houses. These constructive techniques have certainly played an important role in the resistance to earthquake loads.

The following propositions constitute the starting point for the development of an efficient and cost-effective protection strategic plan (Benouar \& Abdessemed-Foufa [16]) for historic buildings:

- Politically, accept that historic buildings are not only objects to preserve but also constitute a national and regional scientific resource

- Promote these traditional seismic protective measures rediscovered in historic sites 
- Contribute to the understanding of these local construction practices, which have protected the historic buildings, monuments and sites

- Analysis and study of the evolution of construction practices over the last few centuries (typology, morphology)

- Characterization of the seismic source parameters related to the area under consideration

- Integration of these techniques into national building codes

- Revival of old professions capable of dealing with historic buildings

- Study the effects of an expected seismic event (i.e. a scenario event) on the site containing a relevant historic structure, using the scenario to characterize the behaviour of different structural typologies, including local seismic cultural elements

- Identify the main historic buildings, monuments and sites at risk in order to take reinforcement actions of the relevant structure by implementing these traditional techniques

- Transmit the traditional seismic preventive techniques to decision makers and end users

- Provide end users (engineers, architects, decision makers, politicians, civil protection personnel, etc.) effective and comprehensible descriptions of the procedure

\section{CONCLUSIONS}

The paraseismic measurements applicable to the old frame for the cultural heritage safeguard explain the good resistance of the buildings to the earthquakes. Research in traditional seismic preventive technology (local seismic culture) constitutes a study which will generate considerable consequences in the medium and long terms for the rehabilitation of cultural and architectural heritage. In fact, the practice of an adequate reinforcement intervention will be assured by the following:

- Developing a sound culture of protection by incorporating local seismic cultures through universities and official authorities

- Developing an intervention methodology for the protection of historic buildings, monuments and sites based on science

- Producing an exhaustive catalogue of traditional preventive techniques including their role and use as a practical tool

- Diffusing knowledge acquired by the training of qualified workers in the field of conservation

- Concentrating on cost-effective and social impacts of the preservation actions

Research requires strong collaboration between scientific organizations; moreover, seismic activity extends well to many countries in Europe - of particular severity in the Mediterranean basin. The most important objective is to develop an integrated approach in seismic and conservation engineering to tackle the problem of improving the capacity of historic and cultural heritage buildings to resist dynamic actions. This task will be made possible by high levels of international expertise in the Mediterranean countries.

\section{REFERENCES}

[1] HCP, 2011, Haut Commissariat au Plan, http://www.hcp.ma/

[2] Hassouni, O., Les techniques et les matériaux traditionnels dans la consolidation et la réhabilitation des bâtiments des médinas: exemple de Fès, 17 November 2013, Architect, Head of Studies and Planning Department, ADER Fez, $1^{\text {er }}$ Colloque International sur les Métiers Traditionnels du Patrimoine Architectural, Oran. 
[3] El Mrabet, T., La Sismicité Historique du Maroc, Thèse de 3ème Cycle, FLSH, Université Mohamed V: Rabat, 1991.

[4] Ministère de l'Habitat, de l'Urbanisme et de l'Aménagement de l'Espace, Université Mohammed V-Agdal, Règlement de Construction Parasismique (RPS 2000), Version révisée, 2011.

[5] Helly, B., Local seismic cultures: a European research program for the protection of traditional housing stock. Annali di Geofisica, XXXVIII(5-6), pp. 791-794, 1995. DOI: $10.4401 /$ ag-4059.

[6] Karababa F., Local Seismic Construction Practices as a Means to Vulnerability Reduction and Sustainable Development. A Case Study in Lefkada Island, Greece, PhD Dissertation, University of Cambridge, 2007.

[7] El Mrabet, T., Les Grands Tremblements de Terre dans la Région Maghrébine et leurs Effets sur l'Homme et l'Environnement, Thèse d'Etat, FLSH, Université Mohamed V: Rabat, 2002.

[8] La Grande Encyclopédie du Maroc, Histoire, ed. M. Kenbib, GEM, Gruppo Walk Over: Rabat, Bergamo, 1986.

[9] CNRST, 2008, Centre National pour la Recherche Scientifique et Technique, www. cnrst.ma/

[10] Ferrigni, F., San-Lorenzello, A la Recherche des Anomalies qui Protègent. Réseau PACT, CUEBS de Ravello, 1990.

[11] El Harrouni, K., Reducing vulnerability of the cultural heritage by rediscovering and re-evaluating local seismic cultures. Proceedings of WCDE, Cultural Heritage Risk Management, Rits-DMUCH: Kyoto, pp. 177-180, 2005.

[12] El Harrouni, K., Protection of historical buildings by re-discovering and re-evaluating local seismic cultures. Proceedings and Monographs in Engineering, Water and Earth Sciences, Protection of Historical Buildings by Reversible Mixed Technologies, PROHITECH 2009, ed. F.M. Mazzolani, CRC Press/Balkema, Taylor \& Francis Group: London, pp. 793-798, 2009.

[13] Laurenti, A., Regard sur la Sismicité Historique de la Commune de Peille dans les Alpes-Maritimes. Groupe APS: Perpignan, 2002.

[14] Abdessemed-Foufa, A., Contribution for a catalogue of earthquake-resistant traditional techniques in Northern Africa: The case of the Casbah of Algiers (Algeria). European Earthquake Engineering Journal 2(5), pp. 23-39, 2005.

[15] Lourenço, P.B., Cultural heritage buildings: Vulnerability to earthquakes and principles for structural conservation. Jurnal Alam Bina, Jilid, 9(3), pp. 65-77, 2007.

[16] Benouar, D. \& Abdessemed-Foufa, A., Reducing the natural and environment disasters on historical and archaeological monuments and sites. Groupe APS: Perpignan, 2002. 